\title{
La remuneración de referencia y el derecho a la pensión en el Sistema Nacional de Pensiones, en el marco del derecho fundamental a la seguridad social The Reference Remuneration and the Right to a Pension in the National Pension System, within the Frame of the Fundamental Right to Social Security
}

Juan R. Gave Maldonado*

http://dx.doi.org/10.21503/lex.v15i19.1380

* Abogado por la Universidad Nacional Hermilio Valdizán de Huánuco. Egresado de la maestría en Derecho Laboral y Seguridad Social de la Universidad Nacional Mayor de San Marcos. Maestro en Derecho Constitucional y Derechos Humanos por la Universidad Alas Peruanas. Profesor de pregrado de la UAP.

E-mail: j_gave@doc.uap.edu.pe

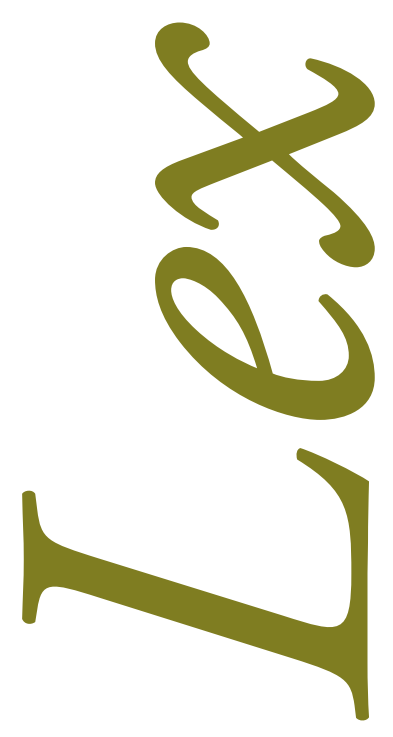

(c) (C) Los autores. Artículo publicado por la Revista Lex de la Facultad de Derecho y Ciencias Políticas de la Universidad Alas Peruanas. Este es un artículo de acceso abierto, distribuido bajo los términos de la Licencia Creative Commons Atribución-N Comercial-Compartir Igual 4.0 Internacional.(http://creativecommons.org/licenses/by-nc-sa/4.0/), que permite el uso no comercial, distribución y reproducción en cualquier medio, siempre que la obra original sea debidamente citada. 


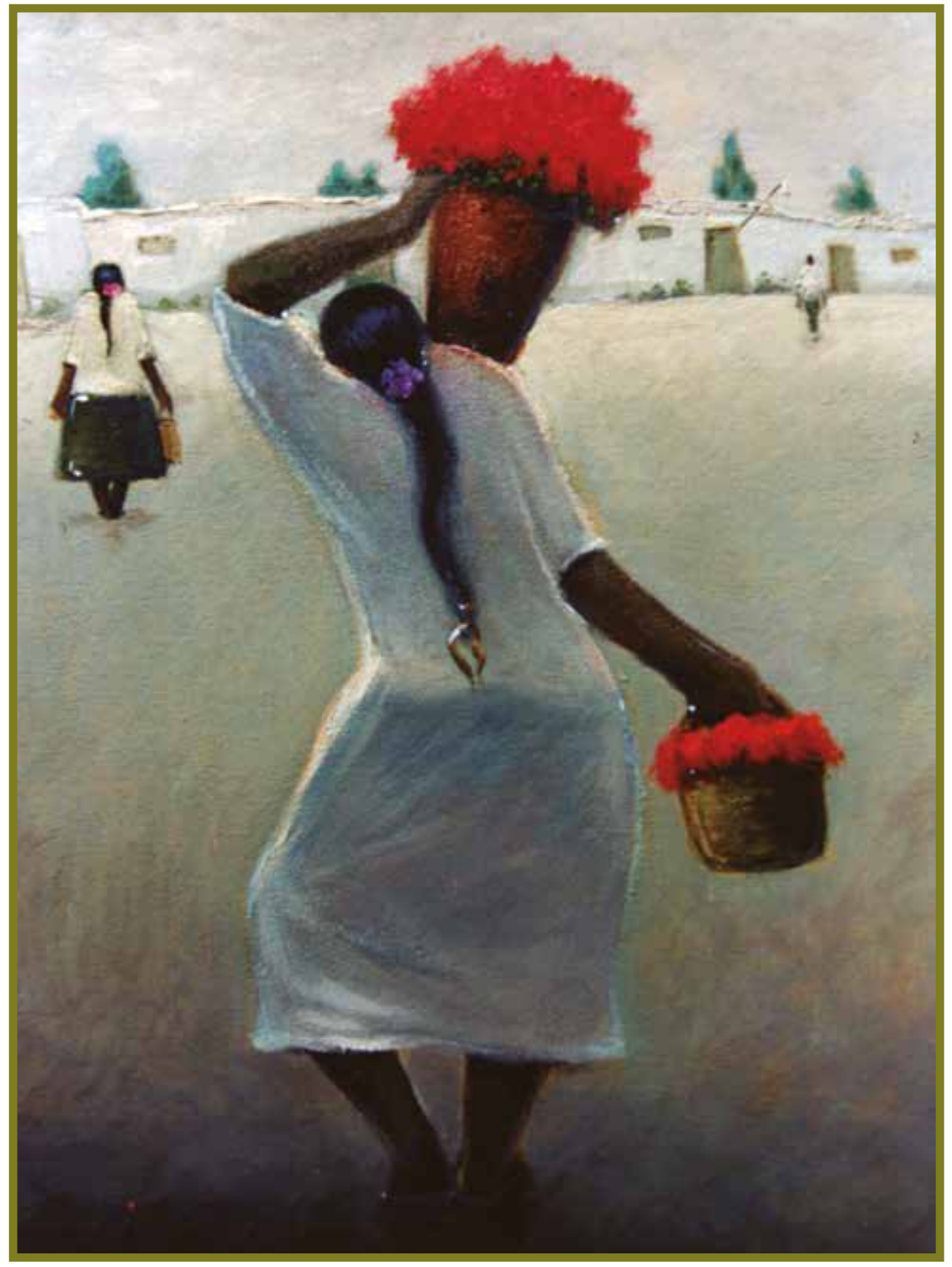

Vendedora. Óscar Allaín 


\section{RESUMEN}

Los diferentes cálculos de la remuneración de referencia en las pensiones de los asegurados en el Sistema Nacional de Pensiones (ONP) se vienen dando de manera tal que se consideran remuneraciones asegurables no efectuadas por los pensionistas durante su vínculo laboral, lo que configura una vulneración al derecho fundamental a la pensión y a la seguridad social consagrada en la Constitución Política del Perú. La presente investigación hace una recopilación de la realidad problemática de la aplicación correcta de las remuneraciones asegurables efectuadas por los asegurados al SNP, haciendo énfasis en la necesidad de determinar el monto de las pensiones considerando solo los meses en que existan remuneraciones asegurables, puesto que estas solo generan la obligación de aportar al sistema y no los meses calendarios, en los cuales se pueden presentar meses en blanco donde no se generen aportes. Tomando estas consideraciones, se busca elevar la calidad de vida de un pensionista a través de un cálculo real y correcto de las remuneraciones de referencia, las que determinaran una pensión justa.

Palabras clave: remuneración de referencia, remuneraciones asegurables, derecho fundamental, calidad de vida.

\section{ABSTRACT}

The different calculations of the reference remuneration of the insured person's pension in the National Pension System - ONP, are done in such a way that the latter are considered insurable remunerations not done by the pensioners during their employment relationship, which constitutes a violation to the fundamental right to a pension and to Social Security stated in the Peruvian Political Constitution. This investigation compiles the problematic reality of the correct application of insurable remunerations contributed by the pensioners to the National Pension System, emphasizing the need to determine the amount of pension considering only those months in which insurable remunerations exist, since only they generate the obligation to contribute to the system but not the calendar months as some months could report insurable remunerations and some months not. These considerations seek to increase the quality of life of a pensioner through a real and correct calculation of the reference remuneration, in order to determine a fair pension.

Key words: remuneration of reference, insurable remunerations, fundamental right, quality of life. 


\section{INTRODUCCIÓN}

La remuneración de referencia que sirve de base para el cálculo del derecho a la pensión en el Sistema Nacional de Pensiones se viene dando como un factor determinante para garantizar el derecho fundamental a la pensión y a la Seguridad Social, siendo prestaciones individualizadas basadas en la prevención del riesgo y en la redistribución de recursos, pues tiene el propósito de coadyuvar en la calidad y el proyecto de vida de los pensionistas del D. Ley No 19990 pertenecientes al Sistema Nacional de Pensiones administrado por el Estado, a través de la Oficina de Normalización Previsional (ONP). En ese contexto, existe un sólido aspecto axiológico dentro de la seguridad social en materia de pensión, que se ve reflejado en el principio de solidaridad, el cual genera que los aportes de los trabajadores activos sirvan de sustento para las prestaciones de pensiones que reciben los pensionistas, como trabajadores jubilados, mediante los cobros mensuales de las pensiones. Así, la Seguridad Social y el Seguro Social se encuentran literalmente ligados. La primera como la protección a la persona humana, independientemente de si es o no trabajador (a través de pensiones), y el segundo como la protección a la persona humana en cuanto es trabajador con relación de dependencia laboral (salud).

En muchos países, como el nuestro, se mantiene esa relación o, más directamente, la relación entre el individuo en cuanto trabajador (característico del Seguro Social) con la Seguridad Social, producto del modelo bismarckiano. Esta relación, por su propia naturaleza, genera efectos en diferentes ámbitos como la política y la economía. De allí nace también la obligatoriedad de los seguros sociales para los trabajadores con relación de dependencia laboral o formal, como se les conoce hoy, dejando la voluntariedad a los independientes. Ello tiene relación también con los aportes, en cuanto la tasa es un obligatorio porcentaje de la remuneración del trabajador.

Dentro de los modelos actuales de seguridad social imperantes a nivel mundial, puede verificarse el tratamiento de dos prestaciones: salud y pensiones. En este trabajo de investigación nos centraremos en la seguridad social en materia de pensiones, en lo referente al cálculo de la remuneración de referencia para efectos de la pensión a otorgarse. 
En esa misma medida, los sistemas de pensiones — uno de los pilares de la Seguridad Social - tienen el carácter contributivo y el aporte significa un descuento de la remuneración, esto es, mantienen todavía esa relación directa con el empleo.

De otra parte y debido al movimiento económico de los sistemas, en los últimos años, el debate sobre la Seguridad Social se ha centrado, casi fundamentalmente, en su aspecto económico y financiero, por cuanto algunos de ellos, de un lado, se encuentran en una difícil situación y, de otro, por la incidencia, importante por cierto, del manejo de sus fondos en el esquema macroeconómico nacional.

Y es que la Seguridad Social en materia de pensiones ha pasado de ser, principalmente, un sistema de prevención y protección social a un sistema de innegable incidencia en la economía general de los países, sobre todo, en los países de América Latina. El desempeño de los fondos de pensiones tiene un porcentaje importante en el crecimiento de la economía. Las modalidades solidarias o mancomunadas de aportación (incluso con aporte económico del Estado) y reconocimiento de beneficios están desapareciendo. La universalidad está lejos de ser alcanzada. Pero, sobre todo, se ha cambiado la participación directa y social del Estado.

El rol social del Estado en la protección ha ido disminuyendo para dar paso a la iniciativa del sector privado. Ahora, el Estado tiene un rol contralor, ya no es el Estado directamente participativo el que incluye la Seguridad Social en su política social. Las instituciones tradicionales de administración autónoma han sido motivo de críticas en el cumplimiento de sus objetivos en cuanto a la protección. Incluso, hace algunos años, la Seguridad Social era vislumbrada como medio de redistribución de la riqueza, además de su principal objetivo de protección social. Hoy, tanto los sistemas públicos como privados, han pasado a tener una influencia casi decisiva en materia económica.

No obstante, como se ha indicado anteriormente, la Seguridad Social debe mantener como objetivo fundamental el de la protección a las personas frente a determinadas contingencias, frente a situaciones o acontecimientos a que se está frecuentemente expuesto, como la vejez, por ejemplo. Ella requiere de una oportuna protección, sobre todo si se trata de una evidente pérdida de su capacidad económica.

La presente investigación toma esta preocupación y se orienta en la propuesta de una de las varias posibles alternativas viables para la solución de este problema. Por ello nos formulamos como problema principal: ¿̇e qué manera la modificatoria del artículo $2^{\circ}$ del D. Ley $N^{o}$ 25967 sobre cálculo de la remuneración de referencia podría garantizar el derecho a la pensión?, y como problemas secundarios: ¿en qué medida el correcto cálculo del promedio mensual de las últimas aportaciones efectivas podría garantizar el derecho a la pensión?, ¿en qué medida la contabilización de las remuneraciones asegurables realizadas por el asegurado podría garantizar el derecho a la pensión? 
Considerando la relación que debe existir entre problemas, objetivos y supuestos, se considera un objetivo general y dos objetivos específicos: determinar que la modificatoria del artículo $2^{\circ}$ del D. Ley No 25967 sobre cálculo de la remuneración de referencia garantizará el derecho a la pensión, establecer que el correcto cálculo del promedio mensual de las últimas aportaciones efectivas garantizará el derecho a la pensión, establecer que la contabilización de las remuneraciones asegurables realizadas por el asegurado, garantizará el derecho a la pensión.

Asimismo, tenemos los siguientes supuestos: la modificatoria del artículo $2^{\circ}$ del D. Ley No 25967, sobre cálculo de la remuneración de referencia, garantizaría el derecho a la pensión, el correcto cálculo del promedio mensual de las últimas aportaciones efectivas garantizaría el derecho a la pensión, la contabilización de las remuneraciones asegurables realizadas por el asegurado garantizaría el derecho a la pensión. Los supuestos a su vez cuentan con categorías que se han identificado en la investigación, como son: remuneración de referencia, promedio mensual, remuneraciones asegurables, derecho a la pensión, derecho a la vida y dignidad humana.

El marco teórico comprende las bases teóricas que nos han permitido sostener nuestra posición sobre el tema planteado, revisando doctrina vinculada a las categorías identificadas. Es así que hemos abordado temas como la remuneración de referencia, que se puede definir como aquel promedio mensual que resulta de las últimas remuneraciones asegurables percibidas por el asegurado, las que nos servirán para el cálculo de la pensión de jubilación. Ello quiere decir que la base para establecer el monto de las pensiones de los asegurados obligatorios y de los asegurados de continuación facultativa es la remuneración de referencia. Es en el artículo 20 del D. Ley No 25967, vigente desde el 18 de diciembre de 1992, donde se han establecido las reglas aplicables al cálculo de la remuneración de referencia

Ahora bien, para la interpretación correcta de la disposición normativa contenida en el artículo $2^{\circ}$ de la citada norma, dado que en ella no se utiliza la frase "meses calendarios", expresión que inequívocamente identificaría a todos los meses correlativos; por el contrario, la norma indica que el cálculo de la remuneración de referencia debe efectuarse obteniéndose el promedio mensual que resulte de dividir entre 36, 48 y/o 60 meses consecutivos inmediatamente anteriores al último mes de aportación; es decir, conforme a la norma, los 36, 48 y/o 60 meses consecutivos que se deben tomar en cuenta para establecer la remuneración de referencia son empezando por el último mes de aportación hacia atrás, esto es, los 36, 48 y/o 60 meses consecutivos en que existan remuneraciones asegurables, puesto que solo estos generan la obligación de aportar al sistema, omitiendo considerar aquellos meses en que no existen remuneraciones asegurables ni tampoco la obligación de aportar.

Esta interpretación no solo tiene sustento en la literalidad de la norma, sino en los principios de equidad y congruencia, pues si conforme a las reglas fijadas por el Decreto Ley No 
19990, para que una persona alcance el derecho pensionario se requiere la concurrencia de los requisitos de edad y años de aportación, resulta contradictorio e injusto que si esta ha alcanzado su derecho a la pensión de jubilación, para la determinación de su remuneración de referencia y, por ende, del monto de su pensión, se le consideren los meses en blanco, en que por algún motivo no trabajó o no pudo acreditar suficientemente la prestación, por cuanto no percibió remuneración asegurable, como "cero aportes", cuando lo cierto es que ya demostrados los años de prestación de servicios y de aportación, debiera considerarse para la determinación del importe pensionario, las 36, 48 y/o 60 remuneraciones asegurables que generó con efectividad; de lo cual resulta que los períodos en que no tuvo remuneraciones asegurables tampoco se deberían tomar en cuenta para establecer el monto de la pensión. ${ }^{1}$

Por otro lado, el promedio mensual, instrumento importante e idóneo en razón al principio de equivalencia para hallar una pensión nivelada, principio según el cual ha de existir igualdad entre lo pagado al inicio y al final de la prestación laboral y la pensión a otorgar al jubilado, de modo que esta debe representar siempre el valor presente actuarial. Es importante este factor al ser crucial para encontrar una adecuada compensación pensionaria, sin importar los diferentes esquemas de pensiones habidas. Para efectos de la pensión de jubilación, podemos definir al promedio mensual como aquello que resulta de dividirse las remuneraciones asegurables de los últimos meses consecutivos inmediatamente anteriores al último mes de aportación. Ahora bien, la base de cálculo para obtener el promedio mensual y por ende la pensión se debe hacer teniendo en consideración la antigüedad de los aportes, los montos acumulados y las necesidades del pensionista, ya que existe una canasta familiar que debe cumplir el trabajador activo, y con la misma razón existe la que deberá satisfacer el trabajador inactivo. Para cada uno de ellos, conforme a la legislación internacional, los Estados han intervenido para cuantificar una pensión mínima, y en ocasiones, también para fijar la máxima. Así, el trabajador activo tiene por remuneración mínima mensual la suma de S/ 850,00 soles (D.S. No 005-2016-TR) y una pensión mínima jubilatoria de S/ 415,00 soles (Disposición Transitoria de la Ley No 27617 e inciso 1 de la Cuarta Disposición Transitoria de la Ley No 28449), estableciendo como pensión jubilatoria máxima la suma de S/ 857,36 soles (D.U. No 105-2011). Al respecto, no se sabe qué criterios se han empleado para ponderar una y otra cifra. Lo que nos hace ver que la intervención pública no es coherente para fijar los lineamientos financieros, teniendo en cuenta que la canasta familiar es de alrededor de S/ 1 500,00 soles. Recordemos que el MEF está detrás de estos reajustes pensionarios, que son hechos a nivel nacional. Las pensiones topes no respetan el principio de rentabilidad de los años de aportes de las sumas vertidas al sistema.

1 Reajuste Pensionario, Casación No 5416-2011 (Segunda Sala de Derecho Constitucional y Social Transitoria de la Corte Suprema de Justicia, 19 de Junio de 2013). 
Dicho lo anterior, el sistema no ejerce un rol tutelar en el dominio de las remuneraciones. El cálculo de la pensión es hecho teniendo en ponderación no las esperanzas de vida nacional o las que pudiera tener el beneficiado, menos las reales aportaciones formuladas, sino sobre la base de criterios que al final permitirán acceder a la pensión máxima indicada.

No podemos dejar de mencionar a la remuneración asegurable que para los fines del sistema se considera al total de las cantidades percibidas por el asegurado por los servicios que presta a su empleador o empresa, cualquiera que sea la denominación que se les dé, con las excepciones señaladas por la propia norma ${ }^{2}$. Dicho ello, podemos definir a las remuneraciones asegurables como aquellos pagos que se realizan mensualmente sean a través del empleador o de manera independiente a un fondo previsional, con la finalidad obtener a futuro el derecho a una pensión en el sistema. En efecto, dichos pagos resultan aquellas aportaciones realizadas al Sistema de Pensiones, en razón de aquellas retenciones hechas al asegurado por el empleador, las que de manera mensual son declaradas al SNP administrado por la ONP.

En la medida de lo posible, es conveniente que el concepto de remuneración asegurable sea igual para todos los regímenes o sistemas de la Seguridad Social, no solo para mantener la uniformidad de los derechos económicos del asegurado sino también para facilitar la gestión contable de las aportaciones por los empleadores y por las cajas de seguros sociales. Esta noción abarca la remuneración por trabajo dependiente en la actividad privada y en la administración pública y las pensiones. ${ }^{3}$

Ha sido importante interpretar a la remuneración mínima asegurable que para el Sistema Nacional de Pensiones "no podrá ser inferior a la remuneración mínima que por disposición legal deba percibir el trabajador por la labor efectuada dentro de la jornada máxima legal o contractual. Cuando no se realice la jornada máxima legal o no se trabaje la totalidad de días de la semana o del mes, la aportación se calculará sobre lo realmente percibido, siempre que se mantenga la proporcionalidad, con la remuneración mínima con la que debe retribuirse a un trabajador, conforme a las normas legales sobre el particular" (D.S. 179-91-PCM del 7.12.1991, artículo 20). Y a la remuneración máxima asegurable, donde las aportaciones de empleadores y asegurados para el Sistema Nacional de Pensiones del D. Ley No 19990 serán calculadas sin topes, sobre la totalidad de las remuneraciones asegurables percibidas por el asegurado, cantidad que para estos efectos tendrá carácter de remuneración máxima asegurable" (D.S. 179-91-PCM del 7.12.1991, artículo 1º).

En esta investigación no podemos dejar de mencionar a las aportaciones en el Sistema Nacional de Pensiones, que para nuestra legislación peruana y dentro de nuestro sistema de

Decreto Ley No 19990, Artículo 8º.

J. Rendon Vásquez, Derecho de la Seguridad Social (Lima: Grijley, 2008). 
pensiones son definidas como aquellas que equivalen a un porcentaje del monto de la remuneración asegurable que percibe el trabajador, porcentaje que se fijará, en cada caso, por Decreto Supremo con el voto aprobatorio del Consejo de Ministros, a propuesta del Consejo Directivo Único de los Seguros Sociales y previo estudio actuarial. ${ }^{4}$ El Sistema Nacional de Pensiones se basa en un criterio avanzado para establecer los períodos de aportación, que dan base a la adquisición del derecho a pensiones y al monto de estas.

A efectos del sistema de pensiones, se consideran los períodos de aportación de los asegurados obligatorios, considerados como todos aquellos meses, semanas o días en que presten o hayan prestado servicios que generen la obligación de abonar las aportaciones correspondientes. Son también períodos de aportación las licencias con goce de remuneraciones otorgadas por ley o por el empleador, así como los períodos durante los cuales el asegurado haya estado en goce de subsidio. Corresponde al empleador cumplir con efectuar la retención y el pago correspondiente por concepto de aportaciones al Sistema Nacional de Pensiones de sus trabajadores. La ONP, para el otorgamiento del derecho a pensión, deberá verificar el aporte efectivo, de acuerdo a lo que establezca el Reglamento para dichos efectos (D. Ley 19990, artículo $70^{\circ}$, según texto dada por la Cuarta Disposición Transitoria y Final de la Ley No 28991).

De lo que podemos desprender que los períodos de aportación tienen dos caracteres: ${ }^{5}$ a) Su unidad es el mes de aportación: "La prestación de servicios remunerados para uno o más empleadores dentro del mes calendario, cualquiera que sea su duración, se considerará como un periodo mensual de aportación. Doce períodos de aportación, aun cuando no fueren consecutivos, hacen un año completo de aportación. "Vale decir que es suficiente que el trabajador haya prestado servicios una parte del mes para que se le considere como período de aportación el mes completo. b) Los períodos de aportación mensuales son acumulativos para conformar los años completos de aportación. Por ejemplo, un trabajador tiene en 1990 ocho meses de aportación, y en 1998 cuatro meses de aportación; por lo tanto, ambos periodos suman un año completo de aportación. En otros términos, para determinar los años completos de aportación se debe sumar todos los meses de aportación que tuvo el trabajador desde que comenzó a prestar servicios remunerados hasta la fecha en que dejó el trabajo para acogerse a la jubilación o hasta la fecha en que fue declarado inválido.

Así mismo, se contemplan los períodos de aportación de los asegurados facultativos, que para los asegurados facultativos se consideran como períodos de aportación los meses por los que paguen aportaciones. Para estos asegurados se consideran, además, los períodos durante los cuales hubiesen sido asegurados obligatorios. No serán consideradas para el otorgamiento y cálculo de las prestaciones, las aportaciones de los asegurados facultativos correspondientes

Decreto Ley No 19990, Artículo 70.
J. Rendon Vásquez, Derecho ... 
al período anterior a la fecha en que se produjo el riesgo, que hubiesen sido abonadas con posterioridad a dicha fecha (D. Ley No 19990, artículo 71º). La razón de esta disposición es impedir que el asegurado facultativo pretenda aumentar sus derechos pagando tardíamente las aportaciones que dejó de pagar en el momento oportuno.

Por otro lado, en la presente investigación resulta relevante mencionar a la Seguridad Social definida como una institución nacida de la solidaridad humana, que se manifiesta en la reacción de ayudar a individuos o grupos en estado de necesidad o desgracia. Este fenómeno social ha tenido diferentes manifestaciones a lo largo de la historia, que han ido evolucionando al ritmo de los cambios sociales y de las necesidades generadas por ello. La Seguridad Social tiene su origen en 1883, con la Ley del Seguro de Enfermedad en Alemania, siendo canciller Otto von Bismarck, y en 1935 con la Ley Social Security Act, donde se usa la expresión seguridad social, que ha alcanzado una más amplia evolución en el presente siglo. ${ }^{6}$ En el año de 1919 surge, como concepto fundamental, la Seguridad Social, a efectos de dotar a los trabajadores y sus familias de una protección especial frente a determinados riesgos que le son inherentes, siendo el más representativo de estos la vejez. El objeto de esta protección es brindar determinadas garantías frente a aquellas contingencias sociales - como se les conoce a los riesgos y siniestros que se presentan - que inexorablemente se habrán de presentar. ${ }^{7}$

Dicho ello, podemos definir a la Seguridad Social, como aquella protección que una sociedad proporciona a los individuos y los hogares para asegurar el acceso a la asistencia médica y garantizar la seguridad del ingreso, en particular en caso de vejez, desempleo, enfermedad, invalidez, accidentes del trabajo, maternidad o pérdida del sostén de familia.

La Seguridad Social está claramente definida en los convenios de la OIT y en los instrumentos de la ONU como un derecho fundamental — aunque en realidad solo una pequeña proporción de la gente en nuestro planeta disfrute del mismo-. Definida en términos generales como un sistema basado en cotizaciones que garantiza la protección de la salud, las pensiones y el desempleo, así como las prestaciones sociales financiadas mediante impuestos, la Seguridad Social se ha convertido en un reto universal en un mundo globalizado. Solo el veinte por ciento de la población mundial tiene una cobertura adecuada en materia de Seguridad Social, mientras que más de la mitad no dispone de ninguna forma de protección social. Aquellos que no están cubiertos tienden a formar parte de la economía informal; por lo general, no están protegidos en su vejez por la Seguridad Social y no están en condiciones de pagar sus gastos de salud. Además, muchas personas tienen una cobertura insuficiente, esto

6 Leonidas Santander Estrada y Eduardo Nonato Santos, Privatización de la Seguridad Social en el Perú (Lima: Grijley E.I.R.L., 2010).

7 Gonzales Hunt, César, Estudios de Derecho del Trabajo y de la Seguridad Social, libro homenaje a Javier Neves Mujica (Lima: Grijley E.I.R.L., 2009). 
es, puede que carezcan de elementos significativos de protección (como la asistencia médica o las pensiones) o que la protección que reciben sea escasa o presente una tendencia a la baja. La experiencia muestra que la gente está dispuesta a cotizar a la Seguridad Social, siempre y cuando esta satisfaga sus necesidades prioritarias.

Resulta de suma importancia en esta investigación mencionar al Sistema Nacional de Pensiones (SNP), creado mediante D. Ley No 19990, promulgado el 24 de abril de 1973 y entra en vigencia el 1 de mayo de 1973, modificado por el D. Ley 20604 del 7 de mayo de 1974. El Reglamento del D. Ley 19990 figura en el Decreto Supremo 011-74-TR, publicado el 31 de julio de 1974. Este sistema se crea en sustitución de los sistemas de pensiones de la caja de pensiones, en ese entonces de la Caja Nacional de Seguro Social, del Seguro Social del Empleado y del Fondo Especial de Jubilación de Empleados Particulares. El SNP es un sistema que incorpora a los trabajadores sujetos al régimen de la actividad privada, obreros, funcionarios y servidores públicos no incorporados al Régimen del Decreto Ley No 20530. Teóricamente, este sistema es de reparto, cuya característica principal consiste en el otorgamiento de prestaciones fijas y contribuciones no definidas en valor suficiente para que la aportación colectiva de los trabajadores financie las pensiones de los actuales jubilados. Este sistema es administrado por la Oficina de Normalización Previsional (ONP), a partir del 1 de junio de 1994.

En el SNP, los asegurados realizan una aportación de $13 \%$ de sus salarios, ${ }^{8}$ y al momento de su jubilación (a los 65 años con al menos 20 años de aportes) reciben una prestación fija sujeta a niveles mínimos y máximos de 415 y 857 respectivamente. Dicha prestación es determinada como un porcentaje de la remuneración de referencia, calculada como el promedio de 36, 48 y/o 60 últimas remuneraciones; y se paga a razón de 14 pensiones al año. Cabe destacar que en este sistema de reparto, debido a la existencia de estas pensiones mínimas y máximas, los trabajadores de menores ingresos obtienen una prestación mayor que la que hubieran obtenido con ahorro personal, mientras que para los trabajadores de ingresos altos, la relación es inversa pues la prestación obtenida es menor a la que les correspondería por su contribución. También se ofrece un adelanto en la jubilación a partir de 50 años (para mujeres) o 55 años (para hombres), exigiéndose un mayor esfuerzo contributivo de 25 y 30 años de cotización, respectivamente, y estableciendo una deducción en el monto de la pensión por cada año de adelanto de la jubilación. Además, el sistema otorga prestaciones por invalidez, viudez, orfandad y ascendencia que equivalen a un porcentaje de la pensión o de la remuneración de referencia, según corresponda. ${ }^{?}$

8 La tasa de aporte estuvo repartida en $3 \%$ el empleado y $6 \%$ el empleador, hasta agosto de 1995, y posteriormente pasó a ser $11 \%$ por cuenta del empleado y a partir de enero de 1997 fue incrementado a $13 \%$.

9 Bernal, Noelia; Ángel Muñoz, Una mirada al Sistema Peruano de Pensiones (Lima: Copyright (C BBVA, 2008). 
Por otro lado, en la presente investigación debemos tener en cuenta lo desarrollado por la doctrina en cuanto a los derechos fundamentales, toda vez que el derecho a la pensión está comprendido como derecho fundamental. Así por ejemplo, Antonio Enrique Pérez Luño define a los derechos humanos ${ }^{10}$ como "un conjunto de facultades e instituciones que, en cada momento histórico, concretan las exigencias de la dignidad, la libertad y la igualdad humana, las cuales deben ser reconocidas positivamente por los ordenamientos jurídicos a nivel nacional e internacional".

Esta definición menciona que el contenido de los derechos fundamentales no es indeterminado en el ámbito temporal. En efecto, esta definición pretende demostrar que la garantía o protección brindada por estos derechos dependen de las necesidades históricas de una sociedad determinada. Pero, al mismo tiempo, no se trataría de cualquier necesidad, sino que debería ser una que, motivada por la importancia del reconocimiento de la persona humana, impulse el desarrollo de su dignidad. Finalmente, precisa que deben ser reconocidos tanto a nivel nacional e internacional, lo cual implica que los Estados pueden reconocer estos derechos ya sea en sus textos constitucionales o ya sea a través de la ratificación de los tratados internacionales.

Por ejemplo, en el caso peruano, el artículo 2 de la Constitución contiene un catálogo de los derechos fundamentales tutelados por el Estado peruano. La regulación sistemática de estos derechos es deficiente. Sin embargo, es relevante mencionar que el artículo 3 del mismo texto contiene una cláusula numerus apertus, la cual permite el reconocimiento progresivo de nuevos derechos. También se ha obligado al Estado, a través de la Cuarta Disposición Final y Transitoria, a respetar los derechos reconocidos a nivel internacional.

El italiano Luigi Ferrajoli ha intentado proveer de algunas herramientas indispensables para poder entender qué derechos deben ser reconocidos como fundamentales. De esta forma, este autor estima que existen tres criterios para poder identificar esta situación: i) la conexión entre los derechos fundamentales y la paz; ii) el nexo entre los derechos fundamentales y el principio de igualdad; $y$ iii) los derechos fundamentales como manifestaciones del derecho del más débil. ${ }^{11}$

Es así que resulta indispensable tener pleno conocimiento de que la Constitución de 1993 dispone en el artículo 11: "El Estado garantiza el libre acceso a prestaciones de salud y a

10 Hasta el momento se ha preferido emplear la expresión "derechos fundamentales". Sin embargo, pese a las alegadas diferencias existentes entre estos derechos y los "derechos humanos", ambas expresiones serán utilizadas de manera aleatoria y sin que importe alguna distinción. Algunos autores reservan la expresión para aquellos consagrados en tratados internacionales sobre derecho humanos, y que representan un límite al accionar estatal. Sin embargo, al menos en el caso peruano, esa distinción carece de sentido, toda vez que las cláusulas constitucionales dan inmediato reconocimiento e incorporan las disposiciones pertinentes sobre tratados de derechos humanos en el orden interno.

11 Oscar Andrés Pazo Pineda, Los derechos fundamentales y el Tribunal Constitucional (Lima: El Búho E.I.R.L., 2014). 
pensiones, a través de entidades públicas, privadas o mixtas...”. En ese contexto, la presente investigación está basada de manera directa en la protección y cumplimiento a cabalidad del derecho fundamental a la pensión, pues se trata de un derecho constitucional, además, de estar consagrado en los tratados internacionales de derechos humanos, de los cuales forma parte el Perú.

En ese contexto, para el desarrollo del derecho a la pensión en la presente investigación se ha considerado la teoría de los derechos fundamentales, la jurisprudencia, la interpretación de la normatividad vigente y la aplicación de la doctrina correspondiente. En ese sentido, citando a Abanto Revilla, la pensión es -independientemente de la contingencia que la origine (enfermedad, accidente, vejez, muerte) — una suma dineraria, generalmente vitalicia, que sustituirá los ingresos percibidos por una persona cuando se presente un estado de necesidad, permanente o transitoria, permitiéndole cubrir sus necesidades básicas, y se otorgará siempre que esta cumpla todos los requisitos previstos legalmente. ${ }^{12}$

Por otro lado, el Tribunal Constitucional ha definido a la pensión como un derecho fundamental de configuración legal, lo cual significa que su origen nace de la Constitución, pero queda librada al legislador ordinario la regulación de los requisitos de acceso y goce de las prestaciones pensionarias. ${ }^{13}$

A partir del fallo del Tribunal Constitucional recaída en el Exp. No 00050-2004-AI/TC, se han determinado los elementos que conforman tanto el contenido esencial del derecho a la pensión como su contenido constitucionalmente protegido. En lo referente al contenido esencial del derecho a la pensión en la doctrina constitucional, los derechos fundamentales no son absolutos sino que pueden estar sujetos a límites legales; sin embargo, la facultad del legislador de restringir estos derechos tiene como barrera infranqueable al denominado "contenido esencial". La garantía del contenido esencial alude a la limitación que tendrá el legislador ordinario, incluso el constituyente, al elaborar normas referidas a derechos fundamentales, de no afectar el núcleo de los elementos mínimos que identifican a un derecho, sin los cuales perdería su identidad.

El Tribunal Constitucional se ha pronunciado sobre el contenido esencial del derecho fundamental a la pensión. En el fundamento 107 de la sentencia recaída en el citado Exp. No 00050-2004-AI/TC ha quedado establecido que su contenido esencial está compuesto por tres elementos: a) el derecho de acceso a una pensión, b) el derecho a no ser privado arbitrariamente de la pensión, c) el derecho a una pensión mínima vital. Estos tres elementos constituyen el núcleo duro del derecho fundamental a la pensión; por tanto, el legislador

12 C. Abanto Revilla, Manual del Sistema Privado de Pensiones (Lima: El Búho E.I.R.L.,2013).

13 Fundamento 120, STC 00050-2004-AI/TC. 
no podrá emitir norma alguna que limite su correcto ejercicio. Es preciso señalar que en los fundamentos 107 y 108 del referido fallo, el Tribunal Constitucional reconoce la existencia de otros elementos que también formarían parte del derecho a la pensión, agrupándolos de manera complementaria en: no esenciales (reajustes y topes) y adicionales (pensiones de sobrevivientes). Estos sí podrán ser revisados y regulados por el legislador para su libre configuración normativa. ${ }^{14}$

El contenido constitucionalmente protegido de un derecho fundamental está constituido por los supuestos que, al derivarse de su contenido esencial, merecen ser tutelados en la sede judicial a través del proceso de amparo. Con esto se busca restringir el acceso a la vía de amparo constitucional, reservándose solo para aquellas pretensiones en las que el derecho constitucional sea la esfera subjetiva afectada, mas no para los casos en los cuales se protegen derechos legales que, por más que estén relacionados al derecho en cuestión, deben ser reclamadas en sede judicial ordinaria, al no derivar directamente del contenido esencial.

En la sentencia recaída en el Exp. 01417-2005-PA/TC, el Tribunal Constitucional tomando como referente los elementos que conforman su contenido esencial- definió el contenido constitucionalmente protegido del derecho a la pensión, ${ }^{15}$ al precisar los reclamos que podrían ser planteados a través del proceso de amparo: a) los supuestos en que, habiendo la persona cumplido los requisitos legales para iniciar el período de aportes al SNP, se deniegue el acceso a la seguridad social; b) los supuestos en que se deniegue a una persona el reconocimiento de una pensión de cesantía, jubilación o invalidez, pese a haber cumplido los requisitos legales para obtenerla (edad, años de aportación, etc.); c) los supuestos en que la pretensión esté relacionada con el monto específico de la pensión, del sistema previsional público o privado, cuando esté comprometido el derecho al mínimo vital; d) los supuestos en los que se deniegue a una persona el reconocimiento de una pensión de sobrevivencia (viudez, orfandad o ascendiente), pese a haber cumplido los requisitos legales para obtenerla; e) los supuestos en los que se afecte el derecho a la igualdad, cuando ante la ausencia de bases razonables, proporcionales y objetivas, se brinde un tratamiento disímil —en el libre acceso a prestaciones pensionarias - a personas que encuentren situación idéntica o sustancialmente análoga. Con este fallo se redujo la cantidad de demandas en materia pensionaria, en vía del amparo, pero no los reclamos en sí, que representan la principal carga del Poder Judicial, ahora formulados masivamente en la vía contencioso-administrativa. ${ }^{16}$

14 C. Abanto Revilla, Manual del Sistema Privado de Pensiones...

15 Fundamento 37) STC 01417-2005-PA/TC.

16 C. Abanto Revilla, Manual del Sistema Privado de Pensiones... 


\section{MATERIAL Y MÉTODO}

\subsection{Tipo o clase de investigación}

La presente tesis corresponde al tipo de investigación sustantiva, en virtud que ha tenido como propósito recoger información de la realidad y enriquecer el conocimiento científico, orientándonos al descubrimiento de principios y leyes.

Dentro de los tipos de investigación tenemos la investigación pura y la investigación básica. Respecto a esta última, es aquella en la que se trabaja sobre la base de investigaciones pasadas y de hechos ya conocido. Este es el caso de la presente investigación, debido a que no se busca crear o descubrir una nueva figura o institución jurídica; al contrario, busca conocerla, a fin de contribuir teóricamente con nuevos aportes respecto de la interpretación y alcances de la remuneración de referencia y el derecho a la pensión en el SNP.

Bajo esta premisa, el presente trabajo de investigación es una disciplina ubicada dentro de las ciencias sociales; el tipo de investigación es básica toda vez que se fundamenta en bases teóricas para la producción de un nuevo concepto, nuevas características, nuevos sujetos, entre otros, de la remuneración de referencia y el derecho a la pensión. Y es una investigación aplicada porque tiene como propósito fundamental dar solución a problemas prácticos a partir de las aportaciones asegurables.

\subsection{Nivel de la investigación}

\section{- Considerando el nivel de análisis}

\section{Investigación descriptiva}

El propósito de la investigación desarrollada tiene características de tipo descriptivo, por cuanto se han descrito de forma detallada las instituciones jurídico-pensionarias necesarias para sostener la importancia de la regulación jurídica de la remuneración de referencia y el derecho a la pensión.

\section{Investigación correlacional}

La investigación es correlacional (descriptiva) porque ha permitido determinar el grado de relación o asociación no causal existente entre categorías identificadas. El tema de investigación desarrollada presenta "la remuneración de referencia" y "el derecho a la pensión", buscando determinar el grado de relación entre ambos factores.

Investigación explicativa

El presente trabajo da cuenta de dos aspectos de la realidad en la remuneración de refe- 
rencia y el derecho a la pensión, resaltando su significación en base a la teoría existente; por lo tanto, se han explicado los hechos o fenómenos necesarios, manteniendo una secuencia y lógicamente deduciéndolos, logrando identificar sus características, elementos y generalidades que permiten reconocer las variables en su contexto real.

\section{- Considerando el tiempo de estudio de las categorías}

\section{Investigación transversal}

En la presente investigación se estudian las categorías señaladas en un tiempo determinado y único. Esto permite medir el grado, la prevalencia, la magnitud, en un determinado momento, de las categorías planteadas.

\subsection{Método de la investigación}

El método científico es un proceso destinado a explicar fenómenos, establecer relaciones entre los hechos y enunciar leyes que expliquen los fenómenos físicos del mundo y permitan obtener, con estos conocimientos, aplicaciones útiles al hombre. El método deductivo logra inferir algo observado a partir de una ley general. Esto lo diferencia del llamado método inductivo, que se basa en la formulación de leyes partiendo de los hechos que se observan. La presente investigación la estudiamos a partir del análisis e interpretación del Decreto Ley No 25967, Ley que modifica el acceso y goce de pensiones de jubilación del D. Ley 19990, y por ello el método es deductivo-inductivo.

\subsection{Diseño de la investigación}

La investigación no experimental es también conocida como investigación ex post facto, término que proviene del latín y significa "después de ocurridos los hechos"; es un tipo de investigación sistemática en la que el investigador no tiene control sobre las categorías porque ya ocurrieron los hechos o porque son intrínsecamente manipulables.

El presente estudio se considera como no experimental con diseño transversal porque no se pueden manipular las variables identificadas, como es el caso de la remuneración de referencia y el derecho a la pensión, que son instituciones jurídicas cuyos conceptos ya están dados.

\subsection{Población}

La población se define como la totalidad del fenómeno a estudiar, donde las unidades de población poseen una característica común, la cual se estudia y da origen a los datos de la investigación. ${ }^{17}$ Por ello, en la presente investigación se han tomado en cuenta características esenciales para seleccionar lapoblación.

17 Mario Tamayo, El proceso de la investigación científica (México: Limusa, 1997), 114. 
En atención a lo anteriormente señalado, es conveniente precisar que la población de la presente investigación comprende a los pensionistas del régimen pensionario del Decreto Ley 19990, en condición de pensionistas ascendientes a 1 065, conforme la fuente de la Oficina de Normalización Previsional. ${ }^{18}$

\section{CUADRO Nº 1. RESUMEN DE LA COMPOSICIÓN DE LA PLANILLA DECRETO LEY Nº 19990 , POR RIESGO, AGOSTO 2015}

(EN CANTIDAD)

\begin{tabular}{|l|c|c|c|c|c|c|c|c|}
\hline \multirow{2}{*}{ CANTIDAD } & \multicolumn{3}{|c|}{ DERECHO PROPIO } & \multicolumn{3}{c|}{ DERECHO DERIVADO } & MIXTOS \\
\cline { 2 - 10 } & $\begin{array}{c}\text { JUBILACIÓN Y } \\
\text { VEJEZ }\end{array}$ & INVALIDEZ & TOTAL & VIUDEZ & ORFANDAD & ASCENDENCIA & TOTAL & $\begin{array}{c}\text { JUBILACIÓN Y } \\
\text { VIUDEZ }\end{array}$ \\
\hline PRESTACIONES 1/ & 347,042 & 22,113 & 369,155 & 135,955 & 10,400 & 1,172 & 147,527 & \\
\hline PENSIONISTAS 2/ & 333,063 & 21,754 & 354,817 & 121,233 & 11,865 & 1,065 & 134,163 & 13,812 \\
\hline $\begin{array}{l}\text { CUENTAS DE } \\
\text { PENSIÓN 3/ }\end{array}$ & 333,506 & 21,807 & 355,313 & 119,719 & 7,486 & 1,168 & 128,373 & 13,520 \\
\hline
\end{tabular}

Fuente - ONP

Nota: No incluye a los pensionistas de la Ley $\mathrm{N}^{\circ} 27803$.

1/ Prestación: es el tipo de pensión que la Seguridad Social otorga a un asegurado o a sus derechohabientes, y son: JUBILACIÓN (en un tiempo se dio VEJEZ), INVALIDEZ, VIUDEZ, ORFANDAD y ASCENDENCIA.

2/ Pensionista: es el asegurado o derechohabiente al que se le reconoce el derecho de una pensión. Un pensionista puede recibir más de una prestación. Ejemplo: viudez y jubilación.

3/ Cuenta de pensión: es el código que se asigna a un pensionista por la prestación que se le otorga. En una misma cuenta de pensión se puede efectuar el pago de varios pensionistas de diferentes prestaciones. Ejemplo: viudez y orfandad. Fuente: Oficina de Normalización Previsional (ONP) - Dirección de Prestaciones.

Elaboración: Oficina de Normalización Previsional (ONP) - Oficina de Planeamiento, Presupuesto y Evaluación de la Gestión.

\subsection{Muestra}

Se entiende por muestra a un subconjunto extraído de la población, claro está a través de técnicas de muestreo, cuyo estudio sirve para inferir características de toda la población. Sin embargo, para la presente investigación, teniendo en consideración que la población en general está afectada en su derecho pensionario y calidad de vida, se ha intencionado la muestra, de tal manera que tenemos a los pensionistas del régimen pensionario del Decreto Ley $\mathrm{N}^{\circ} 19990$, en condición de pensionista ascendientes en 282.

18 Es una institución pública descentralizada del Ministerio de Economía y Finanzas y su misión es orientar sus esfuerzos para lograr el bienestar de los jubilados a través de un trato amable y justo, utilizando procesos eficientes y altos estándares de calidad. Tiene fondos y patrimonio propios, autonomía funcional, administrativa, técnica, económica y financiera, constituyendo un pliego presupuestal. 


\subsection{Técnica}

Una vez que se ha seleccionado el diseño de investigación y la muestra adecuada, lo que sigue es la recolección de datos pertinentes sobre los atributos, conceptos, cualidades o variables involucrados en la investigación.

Recolectar datos implica elaborar un plan detallado de procedimientos que conduzca a reunirlos con un propósito específico; se ha utilizado la técnica e instrumentos, tanto cuantitativos como cualitativos, que es posible que una investigación pueda utilizar, y la nuestra no es ajena a estascaracterísticas.

\subsection{Instrumento}

El instrumento es el medio, la herramienta que va a permitir desplegar la técnica referida. $\mathrm{El}$ instrumento que se empleó es el cuestionario de preguntas de la encuesta, la misma que contiene una serie de preguntas o ítems respecto a una o más variables a medir. Gómez ${ }^{19}$ refiere que básicamente se consideran dos tipos de preguntas: cerradas y abiertas. Las preguntas cerradas contienen categorías fijas de respuesta que han sido delimitadas; las respuestas incluyen dos posibilidades (dicotómicas) o incluir varias alternativas. Este tipo de preguntas permite facilitar previamente la codificación (valores numéricos) de las respuestas de los sujetos. El trabajo de investigación ha considerado a las dicotómicas como la mejor escala para la respuesta de los pensionistas.

\section{RESULTADOS}

TABLA N 1. RESULTADOS DE LA VARIABLE REMUNERACIÓN DE REFERENCIA

\begin{tabular}{|c|c|c|c|c|c|}
\cline { 3 - 6 } \multicolumn{2}{|c|}{} & Frecuencia & $\begin{array}{c}\text { Frecuencia } \\
\text { acumulada }\end{array}$ & $\begin{array}{c}\text { Porcentaje } \\
\text { válido }\end{array}$ & $\begin{array}{c}\text { Porcentaje } \\
\text { acumulado }\end{array}$ \\
\hline \multirow{3}{*}{ Válidos } & 30 & 150 & 53,2 & $53,2 \%$ & $53,2 \%$ \\
\cline { 2 - 6 } & 32 & 132 & 46,8 & $46,8 \%$ & $100,0 \%$ \\
\cline { 2 - 6 } & Total & $\mathbf{2 8 2}$ & $\mathbf{1 0 0 , 0}$ & $\mathbf{1 0 0 , 0} \%$ & \\
\hline
\end{tabular}

Fuente: Cuestionario sobre remuneración de referencia.

19 Francisco Gómez Valdez, Derecho Previsional y de la Seguridad Social (Lima: San Marcos, 2012), 127-128. 


\section{GRÁFICO N 1. REMUNERACIÓN DE REFERENCIA}

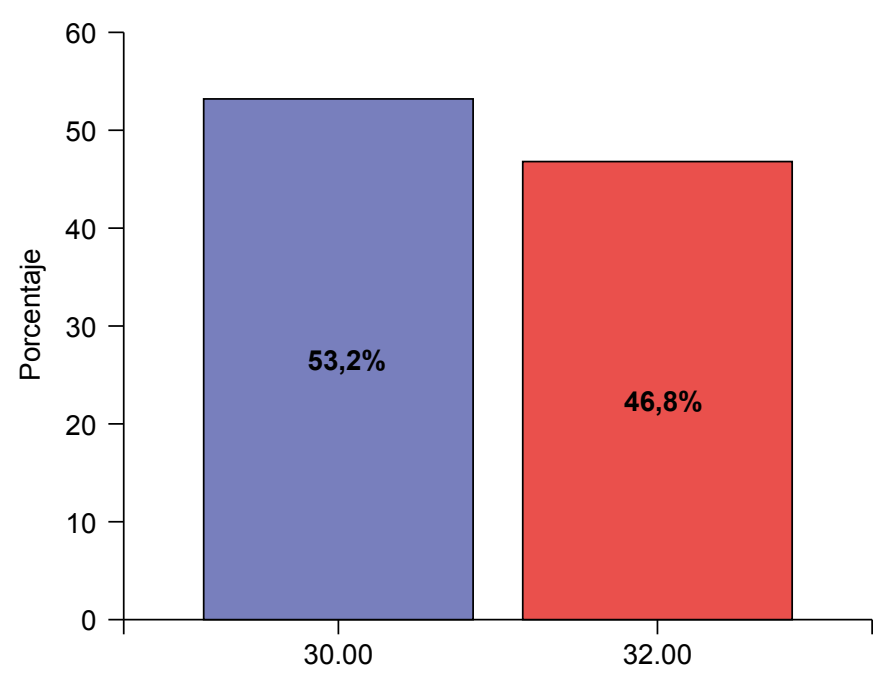

Fuente: Cuestionario sobre remuneración de referencia.

En la tabla No 1 y gráfico $\mathrm{N}^{\circ} 1$ los resultados del cuestionario aplicado a una muestra representativa de 282 pensionistas del régimen pensionario del Decreto Ley $\mathrm{N}^{\circ}$ 19990, en condición de pensionistas ascendientes, respecto a la variable remuneración de referencia, tal como se observa en la distribución de ambas dimensiones: promedio mensual y remuneración asegurable, de la variable remuneración de referencia, donde 150 , que representan al $53,2 \%$, manifiestan sus observaciones respecto a la dimensión promedio mensual, y 132, que equivalen a 46,8\%, lo hacen respecto a la dimensión remuneración asegurable; ello nos lleva a concluir que la mayoría de la muestra no está de acuerdo con lo estipulado respecto a la remuneración de referencia, tal como se evidencia en la información precedente.

TABLA N ${ }^{\circ}$ 2. RESULTADOS DE LA DIMENSIÓN PROMEDIO MENSUAL

\begin{tabular}{|c|c|c|c|c|c|}
\cline { 3 - 5 } \multicolumn{2}{|c|}{} & Frecuencia & $\begin{array}{c}\text { Frecuencia } \\
\text { acumulada }\end{array}$ & $\begin{array}{c}\text { Porcentaje } \\
\text { válido }\end{array}$ & $\begin{array}{c}\text { Porcentaje } \\
\text { acumulado }\end{array}$ \\
\hline \multirow{3}{*}{ Válidos } & 15 & 150 & 53,2 & 53,2 & 53,2 \\
\cline { 2 - 6 } & 17 & 132 & 46,8 & 46,8 & 100,0 \\
\cline { 2 - 6 } & Total & $\mathbf{2 8 2}$ & $\mathbf{1 0 0 , 0}$ & $\mathbf{1 0 0 , 0}$ & \\
\hline
\end{tabular}

Fuente: Cuestionario sobre remuneración de referencia 
GRÁFICO N ${ }^{2}$. PROMEDIO MENSUAL

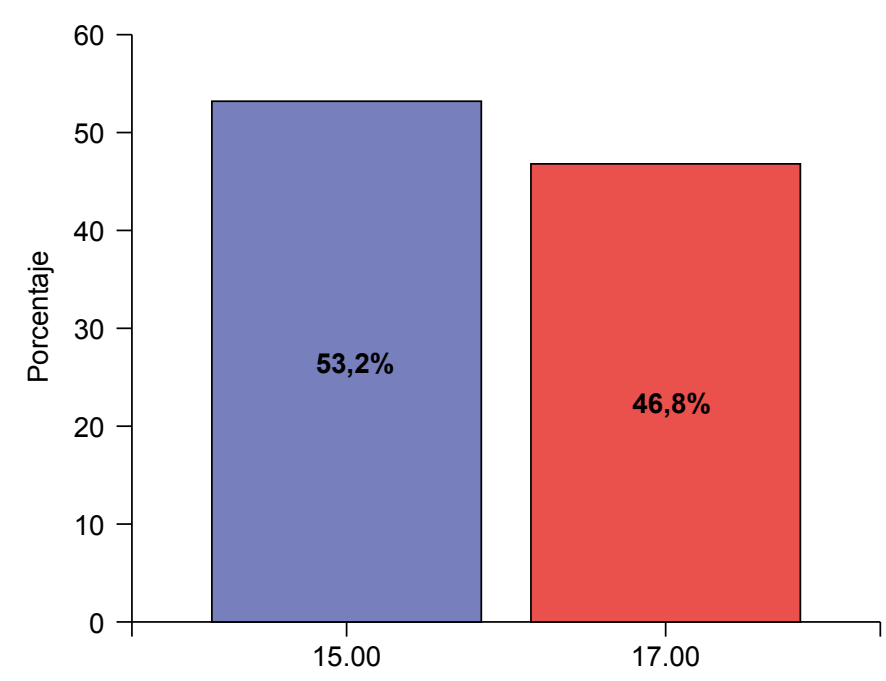

Fuente: Cuestionario sobre remuneración de referencia.

En la tabla № 2 y gráfico $\mathrm{N}^{\circ} 2$, los resultados del cuestionario aplicado a una muestra representativa de 282 pensionistas del régimen pensionario del Decreto Ley $\mathrm{N}^{\circ} 19990$, en condición de pensionistas ascendientes, respecto a la dimensión promedio mensual, donde 150 , que representan al 53,2 \%, manifiestan sus observaciones respecto a la dimensión promedio mensual, y 132, que equivalen a 46,8 \%, lo hacen respecto al promedio mensual; ello nos lleva a concluir que la mayoría de la muestra no está de acuerdo con lo estipulado respecto a la dimensión promedio mensual, tal como se evidencia en la información precedente.

TABLA N ${ }^{\circ}$ 3. RESULTADOS DE LA DIMENSIÓN REMUNERACIÓN ASEGURABLE

\begin{tabular}{|l|c|c|c|c|c|}
\cline { 3 - 6 } \multicolumn{2}{|c|}{} & Frecuencia & $\begin{array}{c}\text { Frecuencia } \\
\text { acumulada }\end{array}$ & $\begin{array}{c}\text { Porcentaje } \\
\text { válido }\end{array}$ & $\begin{array}{c}\text { Porcentaje } \\
\text { acumulado }\end{array}$ \\
\hline \multirow{2}{*}{ Válidos } & 15 & 282 & 100,00 & 100,00 & 100,00 \\
\cline { 2 - 6 } & Total & 282 & 100,00 & 100,00 & \\
\hline
\end{tabular}

Fuente: Cuestionario sobre remuneración de referencia. 


\section{GRÁFICO Nº 3. REMUNERACIÓN ASEGURABLE}

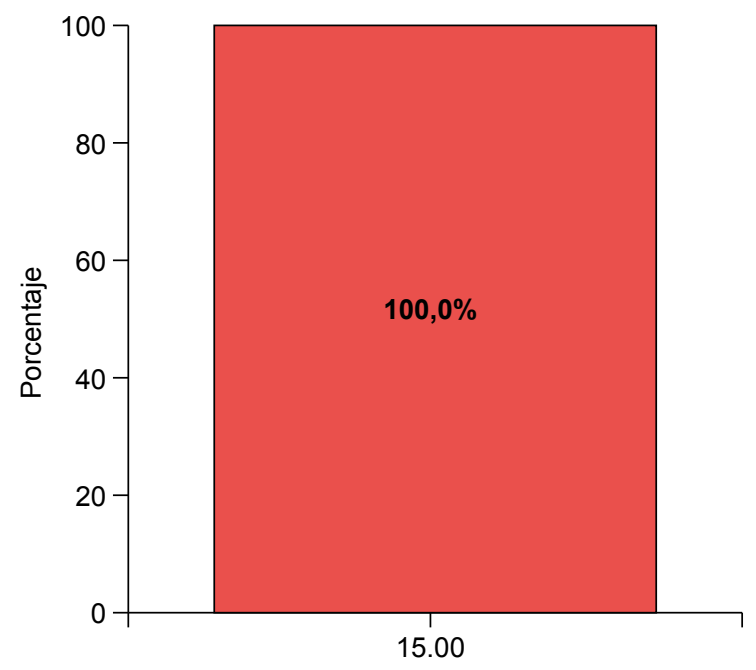

Fuente: Cuestionario sobre remuneración de referencia.

En la tabla No 3 y gráfico $\mathrm{N}^{\circ} 3$, los resultados del cuestionario aplicado a una muestra representativa de 282 pensionistas del régimen pensionario del Decreto Ley $\mathrm{N}^{\circ} 19990$, en condición de pensionistas ascendientes, respecto a la dimensión remuneración asegurable, donde 282, que representan al $100 \%$, manifiestan sus serios cuestionamientos respecto a esta dimensión; esto implica que la gran mayoría está descontenta con la actual forma que tiene el Estado de tratar este tema; sin embargo, refiere que la ONP considera la existencia de la remuneración asegurable en un 100 \%; ello nos lleva a concluir que la mayoría de la muestra está de acuerdo con lo estipulado respecto a la remuneración asegurable, tal como se evidencia en la información precedente.

TABLA N ${ }^{\circ}$. RESULTADOS DE LA VARIABLE DERECHO A LA PENSIÓN

\begin{tabular}{|c|c|c|c|c|c|}
\cline { 2 - 6 } \multicolumn{2}{|c|}{} & Frecuencia & $\begin{array}{c}\text { Frecuencia } \\
\text { acumulada }\end{array}$ & $\begin{array}{c}\text { Porcentaje } \\
\text { válido }\end{array}$ & $\begin{array}{c}\text { Porcentaje } \\
\text { acumulado }\end{array}$ \\
\hline \multirow{4}{*}{ Válidos } & 26 & 50 & 17,7 & 17,7 & 17,7 \\
\cline { 2 - 6 } & 27 & 50 & 17,7 & 17,7 & 35,5 \\
\cline { 2 - 6 } & 31 & 100 & 35,5 & 35,5 & 70,9 \\
\cline { 2 - 6 } & 32 & 82 & 29,1 & 29,1 & 100,0 \\
\cline { 2 - 6 } & Total & $\mathbf{2 8 2}$ & $\mathbf{1 0 0 , 0}$ & $\mathbf{1 0 0 , 0}$ & \\
\hline
\end{tabular}

Fuente: Cuestionario sobre derecho a la pensión. 
GRÁFICO Nº 4. DERECHO A LA PENSIÓN

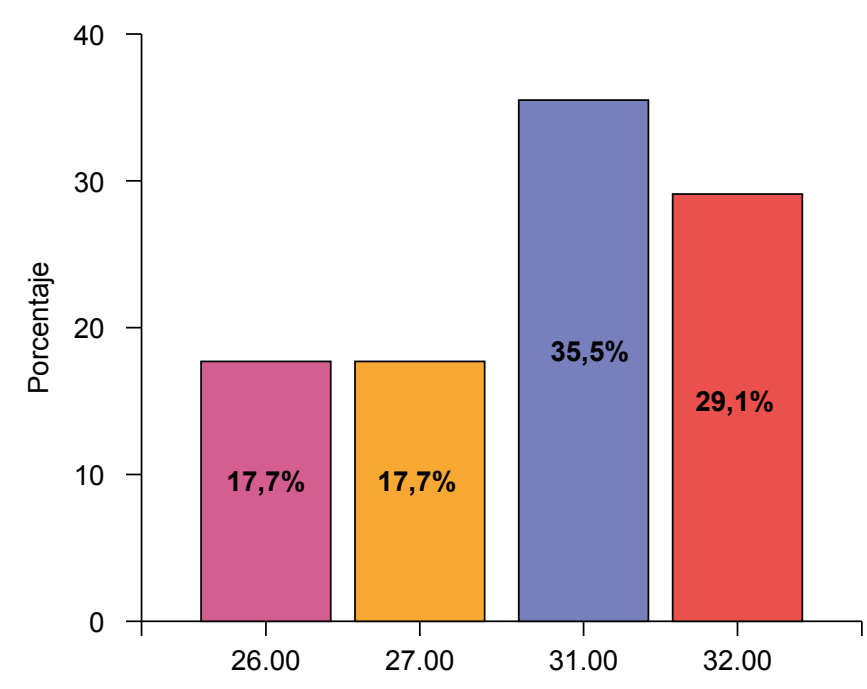

Fuente: Cuestionario sobre derecho a la pensión.

En la tabla No 4 y gráfico $\mathrm{N}^{\circ} 4$, los resultados del cuestionario aplicado a una muestra representativa de 282 pensionistas del régimen pensionario del Decreto Ley $\mathrm{N}^{\circ} 19990$, en condición de pensionistas ascendientes, respecto a la variable derecho a la pensión, tal como se observa en la distribución de las dimensiones: derecho social, derecho a la vida y dignidad humana, donde 50, que representan al 17,17\%; 100, que representan al 35,5 $\%$; y 82 , que representa al $29,1 \%$ respectivamente, se evidencian en las tablas y gráficos siguientes.

TABLA N ${ }^{\circ}$. RESULTADOS DE LA DIMENSIÓN DERECHO SOCIAL

\begin{tabular}{|c|c|c|c|c|c|}
\cline { 3 - 6 } \multicolumn{2}{|c|}{} & Frecuencia & $\begin{array}{c}\text { Frecuencia } \\
\text { acumulada }\end{array}$ & $\begin{array}{c}\text { Porcentaje } \\
\text { válido }\end{array}$ & $\begin{array}{c}\text { Porcentaje } \\
\text { acumulado }\end{array}$ \\
\hline \multirow{3}{*}{ Válidos } & 8 & 50 & 17,7 & $17,7 \%$ & $17,7 \%$ \\
\cline { 2 - 6 } & 10 & 50 & 17,7 & $17,7 \%$ & $35,5 \%$ \\
\cline { 2 - 6 } & 11 & 182 & 64,5 & $64,5 \%$ & $100,0 \%$ \\
\cline { 2 - 6 } & Total & $\mathbf{2 8 2}$ & $\mathbf{1 0 0 , 0}$ & $\mathbf{1 0 0 , 0} \%$ & \\
\hline
\end{tabular}

Fuente: Cuestionario sobre derecho a la pensión. 


\section{GRÁFICO N 5. DERECHO SOCIAL}

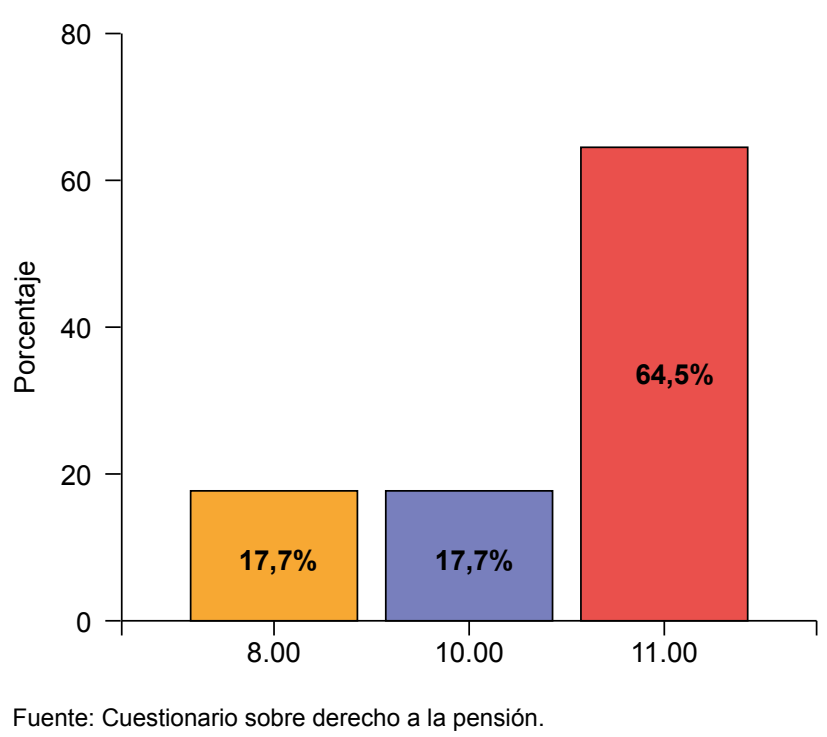

En la tabla No 5 y gráfico $\mathrm{N}^{\circ} 5$, los resultados del cuestionario aplicado a una muestra representativa de 282 pensionistas del régimen pensionario del Decreto Ley $\mathrm{N}^{\circ}$ 19990, en condición de pensionistas ascendientes respecto a la dimensión derecho social, donde 50, que representan al 17,7 \%, manifiestan sus observaciones respecto que si la ONP considera el derecho social de pensiones y si existe aplicación del derecho social a la pensión; 50, que representan al 17,7 \%, manifiestan que la ONP establece medidas para proteger el derecho social a la pensión; y 182, que equivalen al 64,5\%, manifiestan que la ONP identifica el derecho de seguridad social como derecho social; ello nos lleva a concluir que la muestra se halla dispersa respecto a las dimensiones en estudio.

TABLA Nº 6. RESULTADOS DE LA DIMENSIÓN DERECHO A LA VIDA

\begin{tabular}{|c|c|c|c|c|c|}
\cline { 3 - 6 } \multicolumn{2}{c|}{} & Frecuencia & $\begin{array}{c}\text { Frecuencia } \\
\text { acumulada }\end{array}$ & $\begin{array}{c}\text { Porcentaje } \\
\text { válido }\end{array}$ & $\begin{array}{c}\text { Porcentaje } \\
\text { acumulado }\end{array}$ \\
\hline \multirow{3}{*}{ Válidos } & 8 & 50 & 17,7 & $17,7 \%$ & $17,7 \%$ \\
\cline { 2 - 6 } & 9 & 50 & 17,7 & $17,7 \%$ & $35,5 \%$ \\
\cline { 2 - 6 } & 10 & 182 & 64,5 & $64,5 \%$ & $100,0 \%$ \\
\cline { 2 - 6 } & Total & $\mathbf{2 8 2}$ & $\mathbf{1 0 0 , 0}$ & $\mathbf{1 0 0 , 0}$ & \\
\hline
\end{tabular}

Fuente: Cuestionario sobre derecho a la pensión 
GRÁFICO N ${ }^{\circ}$. DERECHO A LA VIDA

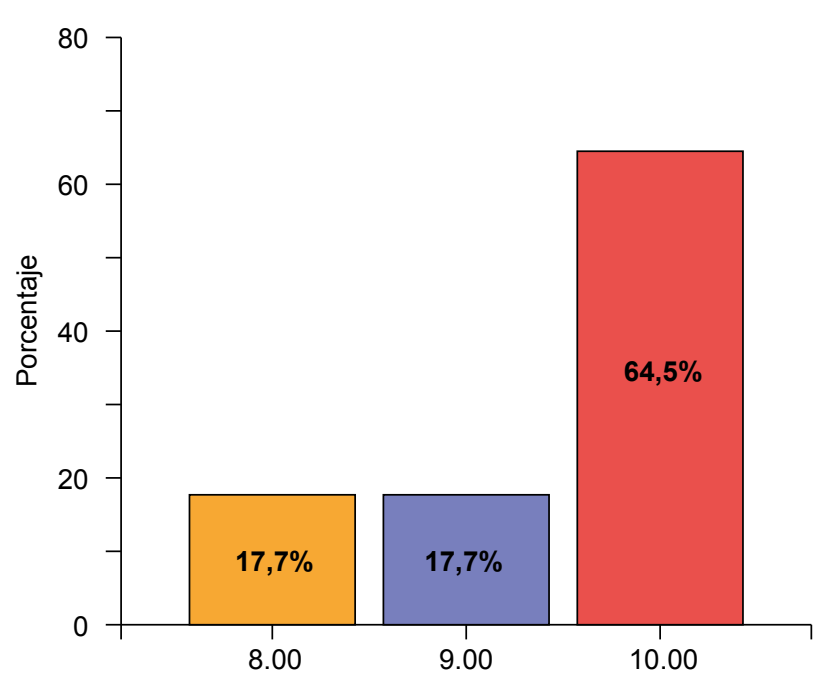

Fuente: Cuestionario sobre derecho a la pensión.

En la tabla No 6 y gráfico $\mathrm{N}^{\circ} 6$, los resultados del cuestionario aplicado a una muestra representativa de 282 pensionistas del régimen pensionario del Decreto Ley $\mathrm{N}^{\circ}$ 19990, en condición de pensionistas ascendientes respecto a la dimensión derecho a la vida, donde 50 , que representan al 17,7 \%, manifiestan sus observaciones respecto que si la ONP corrige desigualdades de la pensión de jubilados y si existe consideración al derecho vida en otorgamiento de pensión; 50, que representan al 17,7 \% manifiestan que la ONP explica que la pensión otorgada es un derecho a la vida y la ONP informa el derecho a la vida como derecho fundamental, y 182, que equivalen al 64,5\%, manifiestan que la ONP establece criterios para garantizar el derecho a la vida y la ONP considera el derecho a la vida en el cálculo de pensión; ello nos lleva a concluir que la muestra se halla dispersa respecto a las dimensiones en estudio.

TABLA N ${ }^{\circ}$. RESULTADOS DE LA DIMENSIÓN DIGNIDAD HUMANA

\begin{tabular}{|c|c|c|c|c|c|}
\cline { 3 - 6 } \multicolumn{2}{c|}{} & Frecuencia & $\begin{array}{c}\text { Frecuencia } \\
\text { acumulada }\end{array}$ & $\begin{array}{c}\text { Porcentaje } \\
\text { válido }\end{array}$ & $\begin{array}{c}\text { Porcentaje } \\
\text { acumulado }\end{array}$ \\
\hline \multirow{4}{*}{ Válidos } & 8,00 & 50 & 17,7 & 17,7 & 17,7 \\
\cline { 2 - 6 } & 9,00 & 50 & 17,7 & 17,7 & 35,5 \\
\cline { 2 - 6 } & 10,00 & 50 & 17,7 & 17,7 & 53,2 \\
\cline { 2 - 6 } & 11,00 & 132 & 46,8 & 46,8 & 100,0 \\
\cline { 2 - 6 } & Total & $\mathbf{2 8 2}$ & $\mathbf{1 0 0 , 0}$ & $\mathbf{1 0 0 , 0}$ & \\
\hline
\end{tabular}

Fuente: Cuestionario sobre derecho a la pensión. 


\section{GRÁFICO N 7. DIGNIDAD HUMANA}

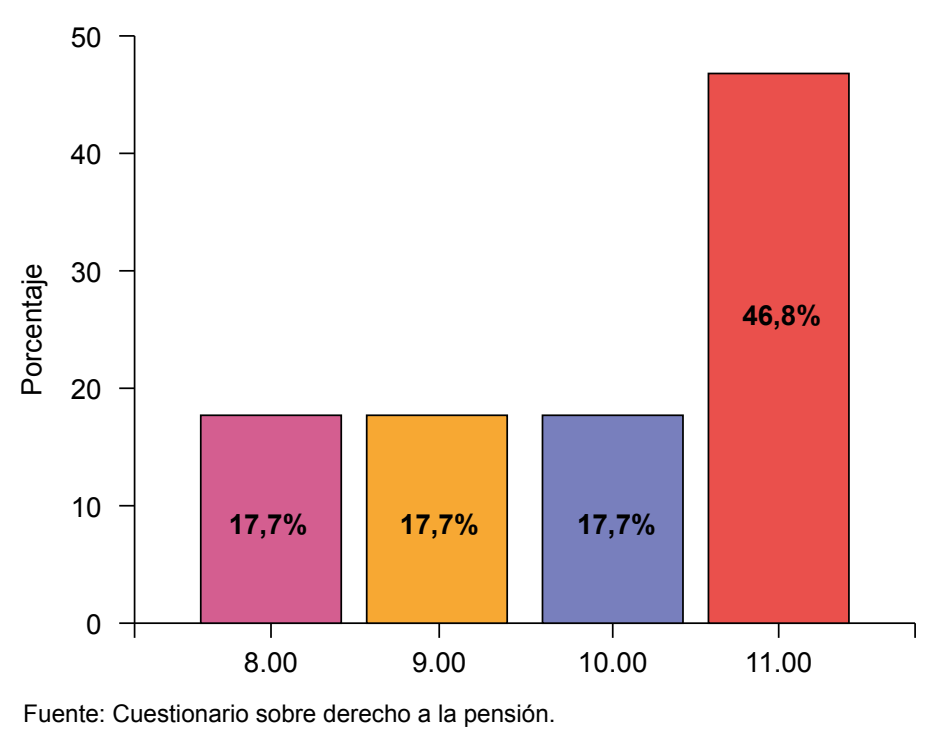

En la tabla $\mathrm{N}^{\circ} 7$ y gráfico $\mathrm{N}^{\circ} 7$, los resultados del cuestionario aplicado a una muestra representativa de 282 pensionistas del régimen pensionario del Decreto Ley $\mathrm{N}^{\circ} 19990$, en condición de pensionistas ascendientes respecto a la dimensión dignidad humana, donde 50 , que representan al 17,7 \%, manifiestan sus observaciones respecto que si en la ONP existe consideración a la dignidad humana en la pensión otorgada y si la ONP discrepa sobre el derecho a la dignidad humana en su condición de pensionista; 50, que representan al 17,7 $\%$, manifiestan que la ONP identifica que del cálculo de pensión depende una vida digna; 50 , que representan al $17,7 \%$, manifiestan que la ONP considera que la dignidad humana es derecho fundamental, y 132 , que equivalen al $46,8 \%$, manifiestan que la ONP aplica el derecho la dignidad humana en forma igualitaria; ello nos lleva a concluir que la muestra se halla dispersa respecto a las dimensiones en estudio.

\section{DISCUSIÓN}

Pensamos que la remuneración de referencia y el derecho a la pensión en el Sistema Nacional de Pensiones de los pensionistas del régimen del Decreto Ley N $^{\circ} 19990$ se halla en una situación preocupante y es tarea esencial del Estado Peruano velar por la integridad e intangibilidad de los derechos laborales, concretamente los referidos a la jubilación y seguridad social. En tales circunstancias y a la luz de los resultados de la presente tesis, tomamos como referencia los antecedentes y teorías respecto al tema.

También consideramos que es tarea de las instituciones involucradas en lo referente a la remuneración de referencia y el derecho a la pensión actuar adecuadamente y sobre todo garantizar la plena vigencia de estos derechos adquiridos. 
Debido a estos planteamientos es que hemos querido estudiar la remuneración de referencia y el derecho a la pensión en el Sistema Nacional de Pensiones (ONP, Lima, 2016), tema al que creemos no se le da la debida relevancia, a pesar de la importancia gravitante que tiene.

En relación a los resultados de la aplicación de los cuestionarios, para ambas variables se evidencia que existe una relación significativa entre la remuneración de referencia y el derecho a la pensión en el Sistema Nacional de Pensiones (ONP, Lima, 2016), tal como se vislumbra en la tabla $\mathrm{N}^{\circ} 8$, que refiere que al correlacionar los resultados totales de la variable remuneración de referencia y la variable derecho a la pensión, se obtiene un valor de $\mathrm{r}$ de Pearson $\mathrm{r}=$ 0,747 , lo que indica que existe una correlación positiva alta.

Estos datos se ven respaldados con las afirmaciones de Eduardo Marcos Rueda, que arriba a la conclusión de que en el Sistema Nacional de Pensiones, como se ha podido apreciar, el cálculo se basa en la denominada remuneración de referencia, es decir, en el promedio percibido por el trabajador en determinado número de meses anteriores a su cese laboral (actualmente, 36, 48 o 60 meses); si en estos periodos la remuneración (para los trabajadores) o ingreso (para los asegurados facultativos) es baja, producto de un subempleo o empleo a tiempo parcial, la influencia seguirá siendo determinante puesto que el cálculo general de la pensión de jubilación se verá disminuida. ${ }^{20}$

Además, la jubilación es la prestación más importante en los sistemas de pensiones en nuestro país. Su derecho se obtiene al cumplimiento de dos requisitos: edad y aportaciones en el Sistema Nacional de Pensiones, y solamente edad en el caso del sistema privado. Dos aspectos fundamentales son el cumplimiento de tales requisitos y el cálculo para determinar su monto. Las modificaciones suscitadas en el Sistema Nacional de Pensiones a partir de los 90 estuvieron dirigidas a tratar de equilibrar su régimen económico financiero y a posibilitar el traslado de sus afiliados al Sistema Privado de Pensiones. ${ }^{21}$ Finalmente, consideramos que esta investigación es un aporte que permitirá contribuir a futuras investigaciones y nuevos métodos de abordaje para el tratamiento de la remuneración de referencia y la variable derecho a la pensión.

\section{CONCLUSIONES}

1. La modificatoria del artículo $2^{\circ}$ del D. Ley $N^{\circ} 25967$ sobre cálculo de la remuneración de referencia resulta necesaria por cuanto permitirá que las pensiones de los pensionistas del régimen del D. Ley $\mathrm{N}^{\circ} 19990$ pertenecientes al Sistema Nacional de Pensiones resulten las más equilibras y ajustadas a la remuneración asegurable que percibía el asegurado durante

20 E. Marcos Rueda, La retroactividad en materia de pensiones: aplicación del Decreto Ley No 25967 (Lima: Universidad Nacional Mayor de San Marcos, 2011).

21 Congreso de la República, Decreto Legislativo No 19990 (Lima: Congreso de la República, 1974). 
su actividad laboral, logrando de esta manera garantizar el derecho fundamental a la pensión y a la seguridad social digna y humana, que garantice el equilibrio y la igualdad en los niveles socioeconómicos de los pensionistas.

2. El correcto cálculo del promedio mensual de las últimas aportaciones efectivas realizadas por el asegurado permitirá que los pensionistas del régimen del Decreto Ley N 19990 obtengan mayores pensiones que las otorgadas por una aplicación inadecuada de la norma, al hacerse una interpretación errónea de la misma por los funcionarios de la Oficina de Normalización Previsional, lo que vulnera el derecho fundamental a la obtención de una pensión digna y humana que garantice elevar la calidad de vida de los jubilados.

3. La contabilización de las remuneraciones asegurables efectuadas por el asegurado conducirá a que todos los meses de aportaciones debidamente pagadas al SNP sean debidamente computadas para reunir los años de aportes que la norma prevé a efectos del acceso y goce las pensiones del régimen del $\mathrm{D}$. Ley $\mathrm{N}^{\circ} 19990$, lo cual nos conducirá a garantizar el derecho fundamental a la pensión y a una seguridad social digna y humana como pilares de la Constitución y de los Tratados internacionales sobre Derechos Humanos.

\section{VI. .RECOMENDACIONES}

1. Elaborar un anteproyecto de ley de modificatoria del artículo $2^{\circ}$ del D. Ley $\mathrm{N}^{\circ} 25967$ sobre cálculo de la remuneración de referencia, siendo la propuesta planteada la siguiente: "Para el cálculo de la remuneración de referencia a la que hace mención lo señalado en el artículo $2^{\circ}$ del Decreto Ley $N^{\circ} 25967$ se debe tomar en cuenta el promedio mensual que resulte de dividir entre 36,48 y 60 , respectivamente, el total de remuneraciones asegurables de los últimos 36, 48 y 60 meses consecutivos inmediatamente anteriores al último mes de aportación; considerando para ello solo los meses en que existan remuneraciones asegurables, porque solo estos generan la obligación de aportar al sistema y no los meses calendario, en los cuales se pueden presentar meses donde no se generen aportes al sistema". ${ }^{22}$

2. Ante la continua operatividad en el mal cálculo del promedio mensual de las últimas aportaciones efectivas, hechas por el ente administrativo a cargo de la ONP, proponemos la creación de órganos de control y supervisión que realicen trabajos de reevaluación y recálculo de la remuneración de referencia teniendo como base las aportaciones efectivamente efectuadas por el asegurado, y de esa manera evitar la vulneración del derecho fundamental a la pensión y a una seguridad social digna; además, nos permitirá reducir la excesiva carga administrativa y judicial que existen hoy en día.

22 Casación N ${ }^{\circ}$ 2602-2013-Piura, Segunda Sala de Derecho Constitucional y Social de la Corte Suprema de Justicia. 
3. Como medida de la contabilización de las remuneraciones asegurables efectuadas durante el vínculo laboral del asegurado, planteamos el acceso directo a las planillas de los empleadores que se encuentra en custodia de la Oficina de Normalización Previsional (ONP), a efectos de constatar y verificar la correcta contabilización de todas las remuneraciones asegurables realizadas por el empleador; de esa manera, además de garantizar el derecho al acceso público de información que la Constitución contempla, esto conducirá al cálculo real de la remuneración de referencia del asegurado en base a la información detallada registrada en las respectivas planillas.

\section{REFERENCIAS}

- Abanto Revilla, C. Manual del Sistema Privado de Pensiones. Lima: El Búho E.I.R.L., 2013.

- Bernal, Noelia; Ángel Muñoz. Una mirada al Sistema Peruano de Pensiones. Lima: Copyright (C) BBVA, 2008.

- Congreso de la República. Decreto Legislativo N 19990. Lima: Congreso de la República, 1974.

- Gómez Valdez, Francisco. Derecho Previsional y de la Seguridad Social. Lima: San Marcos, 2012.

- Gonzales Hunt, César. Estudios de Derecho del Trabajo y de la Seguridad Social. Libro homenaje a Javier Neves Mujica. Lima: Grijley E.I.R.L., 2009.

- Marcos Rueda, E. La retroactividad en materia de pensiones: aplicación del Decreto Ley $N^{o}$ 25967. Lima: Universidad Nacional Mayor de San Marcos, 2011.

- Pazo Pineda, Oscar Andrés. Los derechos fundamentales y el Tribunal Constitucional. Lima: El Búho E.I.R.L., 2014.

- Rendón Vásquez, J. Derecho de la Seguridad Social. Lima: Grijley, 2008.

- Santander Estrada, Leonidas y Eduardo Nonato Santos. Privatización de la Seguridad Social en el Perú. Lima: Grijley E.I.R.L., 2010.

- Tamayo, Mario. El proceso de la investigación científica. México: Limusa, 1997.

Recibido: 21/4/2017

Aprobado: 26/5/2017 